\title{
Supporting Information Design molecular topology for wet-dry adhesion
}

Jiawei Yangl, 2, Ruobing Bail, 2, Jianyu Li ${ }^{1,3,4}$, Canhui Yangl, 2, Xi Yao ${ }^{1,2}$, Qihan Liu ${ }^{1,2}$, Joost J. Vlassak ${ }^{l}$, David J. Mooney ${ }^{l, 3}$ and Zhigang Suo ${ }^{1,2^{*}}$

${ }^{1}$ John A. Paulson School of Engineering and Applied Sciences, Harvard University, Cambridge, MA 02138, USA

${ }^{2}$ Kavli Institute for Nanobio Science and Technology, Harvard University, Cambridge, MA 02138, USA

${ }^{3}$ Wyss Institute for Biologically Inspired Engineering, Harvard University, Cambridge, MA 02138, USA

${ }^{4}$ Department of Mechanical Engineering, McGill University, Montreal, QC H3A 0C3, Canada

* To whom correspondence should be addressed. Email: suo@seas.harvard.edu 
a Topology of hydrogel-elastomer adhesion by attaching (Facile fabrication of hydrogel devices)

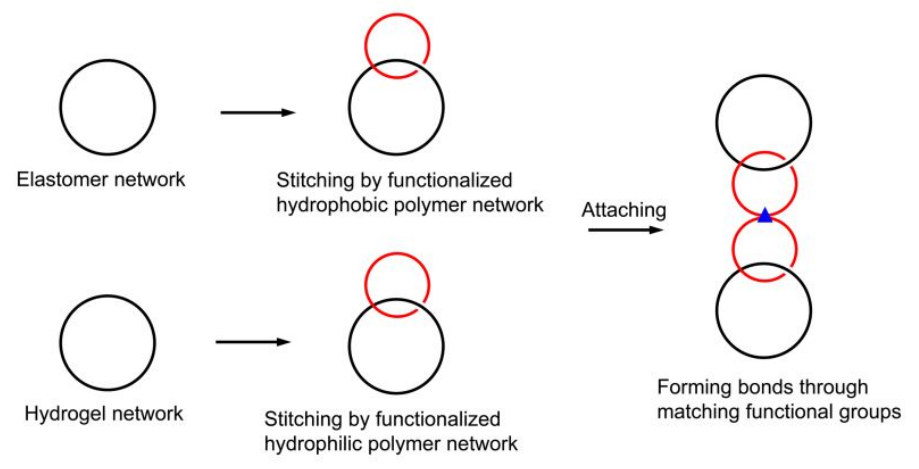

b Topology of hydrogel-elastomer adhesion by coating and printing (Rapid prototyping and scalable manufacturing of hydrogel devices)

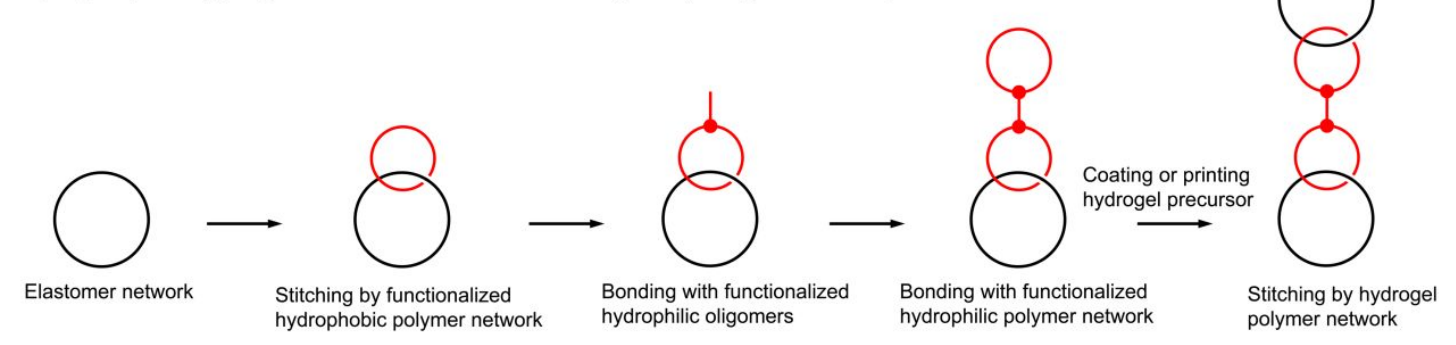

C Topology of tissue-elastomer adhesion by gluing (Medical implants)
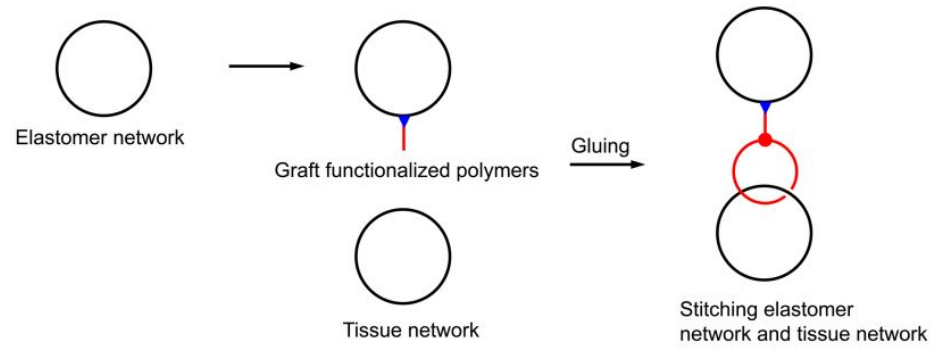

d Topology of metal-hydrogel-tissue adhesion by gluing (Wearable electronics)

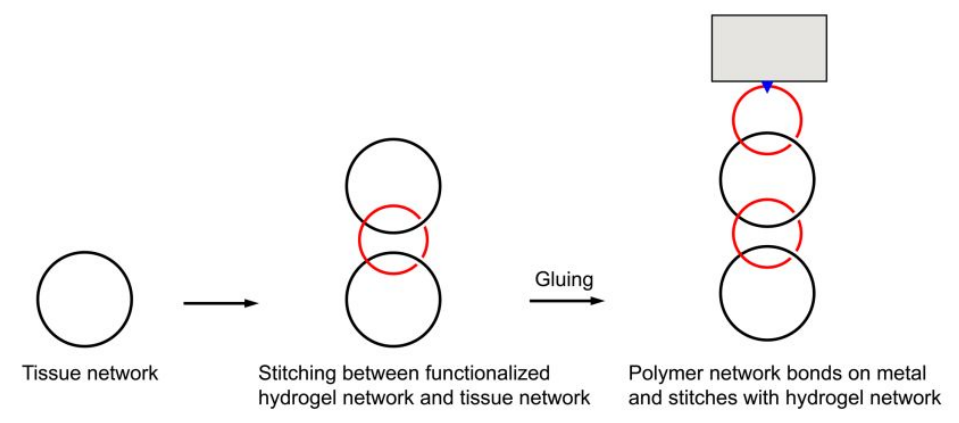

Figure S1. Some other topologies proposed for potential applications. (a) A stitch-bond-stitch topology of hydrogel-elastomer adhesion by attaching. (b) A stitch-bond-bond-stitch topology of hydrogel-elastomer adhesion by coating and printing. (c) A bond-bond-stitch topology of tissueelastomer adhesion by gluing. (d) A bond-stitch-stitch-stitch topology of metal-hydrogel-tissue adhesion by gluing. 


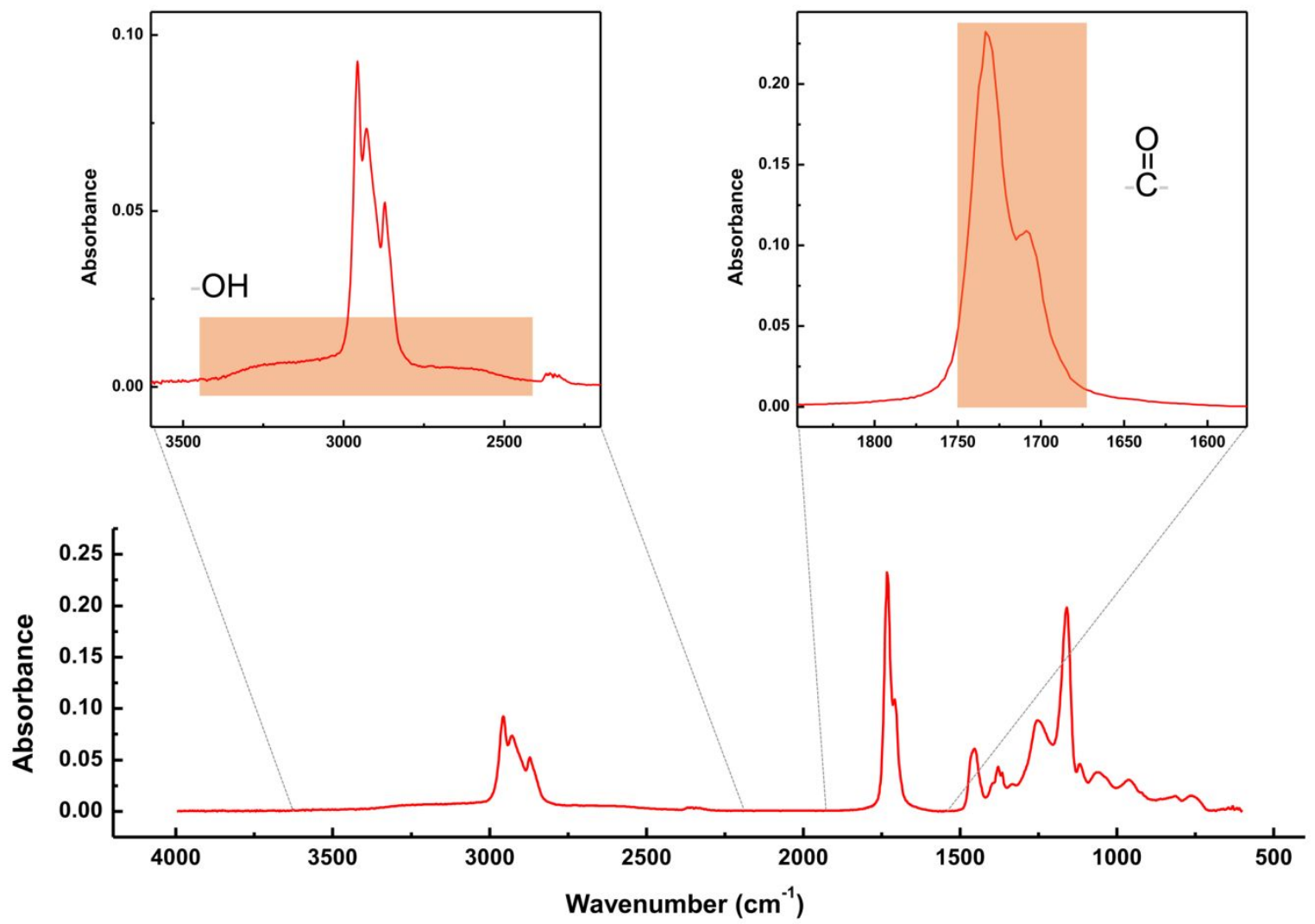

Figure S2. The chemistry of the VHB elastomer. The Fourier-transform infrared spectroscopy (FTIR) shows the VHB elastomer has a sharp peak in the range of $1700-1750 \mathrm{~cm}^{-1}$ and a broad but shallow peak in the range of $2500-3500 \mathrm{~cm}^{-1}$. These peaks correspond to the $\mathrm{C}=\mathrm{O}$ stretch and $\mathrm{O}-$ $\mathrm{H}$ stretch, respectively, and indicate the presence of ketone and carboxylic acid groups. 


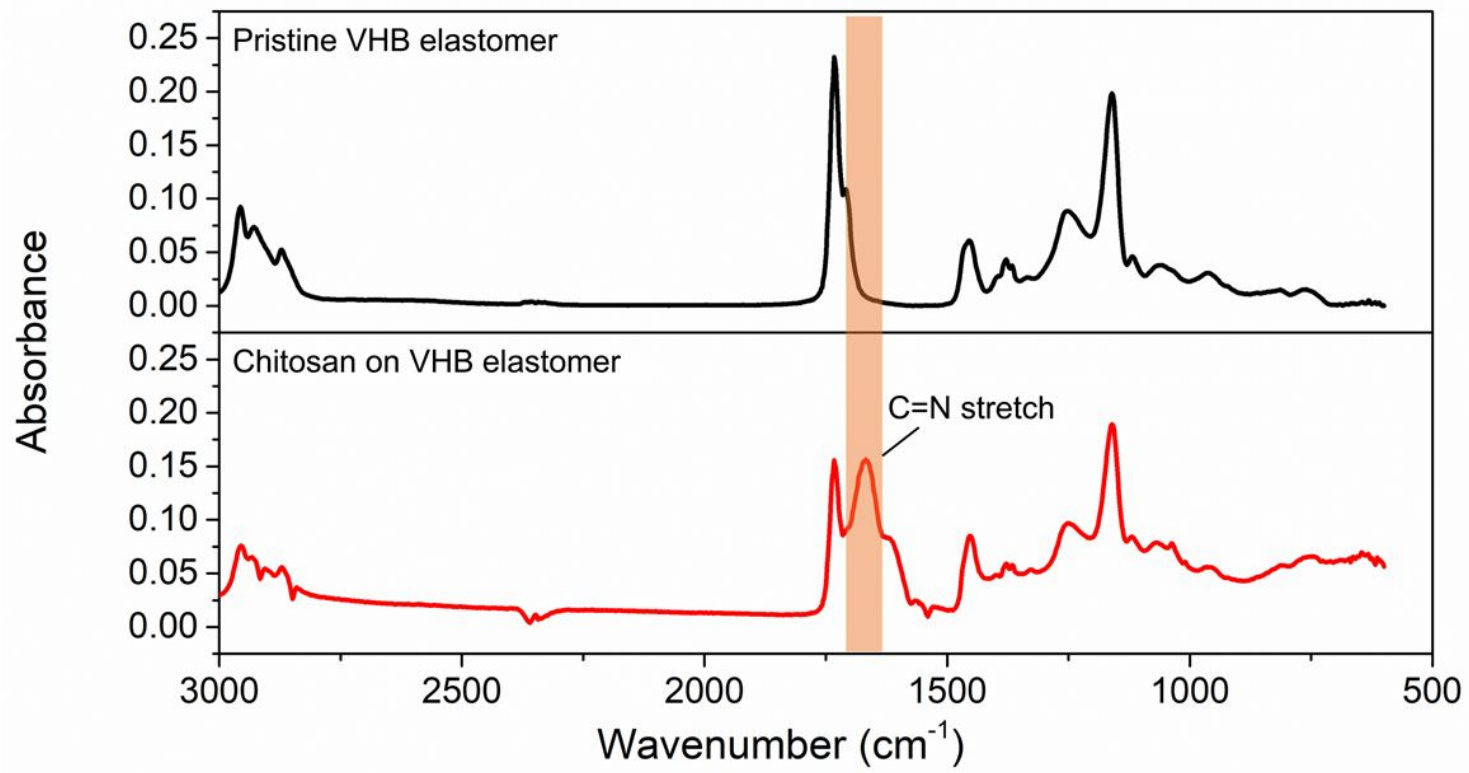

Figure S3. Formation of imine bonds. The FTIR spectrum of chitosan bonded on an VHB elastomer shows a peak in the range of $1640-1690 \mathrm{~cm}^{-1}$, which corresponds to the imine $\mathrm{C}=\mathrm{N}$ stretch. In contrast, the FTIR spectrum of the pristine VHB elastomer does not show this peak. 
a

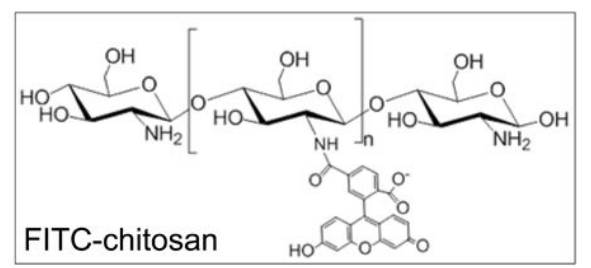

C

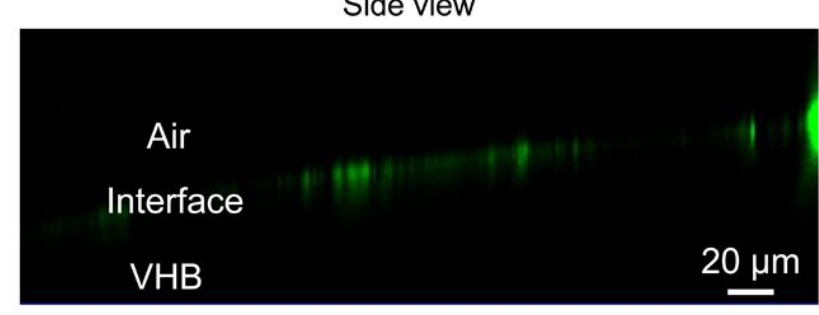

Side view

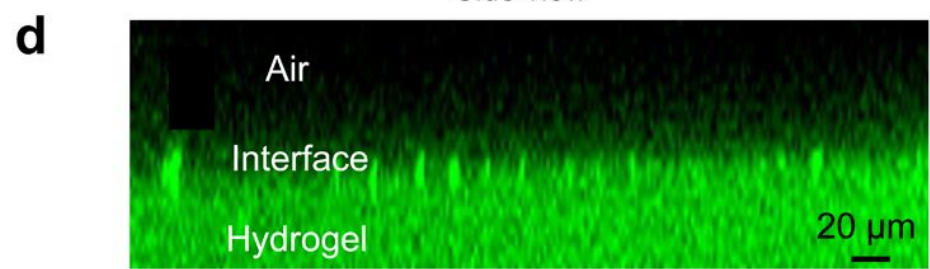

b

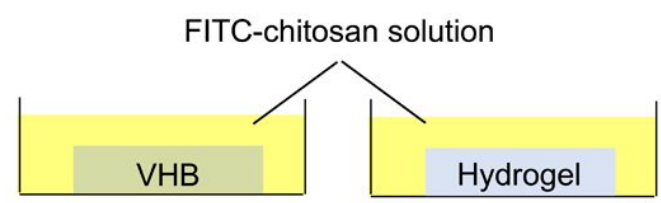

Top view

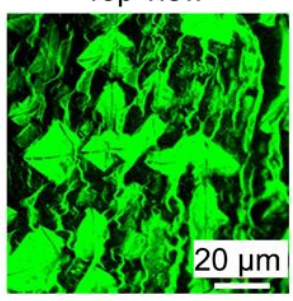

Top view

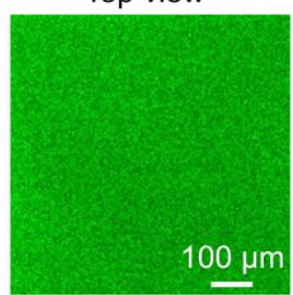

Figure S4. Chitosan chains can diffuse into the PAAM hydrogel, but not into the VHB elastomer. (a) The molecular structure of the FITC-chitosan. (b) A piece of PAAM hydrogel and a piece of VHB are soaked in the FITC-chitosan solution for one day before confocal imaging. (c) Confocal image shows that the FITC-chitosan chains cannot diffuse into the VHB elastomer (side view), but localize on the surface and form an inhomogeneous phase (top view). (d) Confocal image shows that the FITC-chitosan chains can diffuse into the hydrogel (side view), and form a homogeneous phase (top view). 

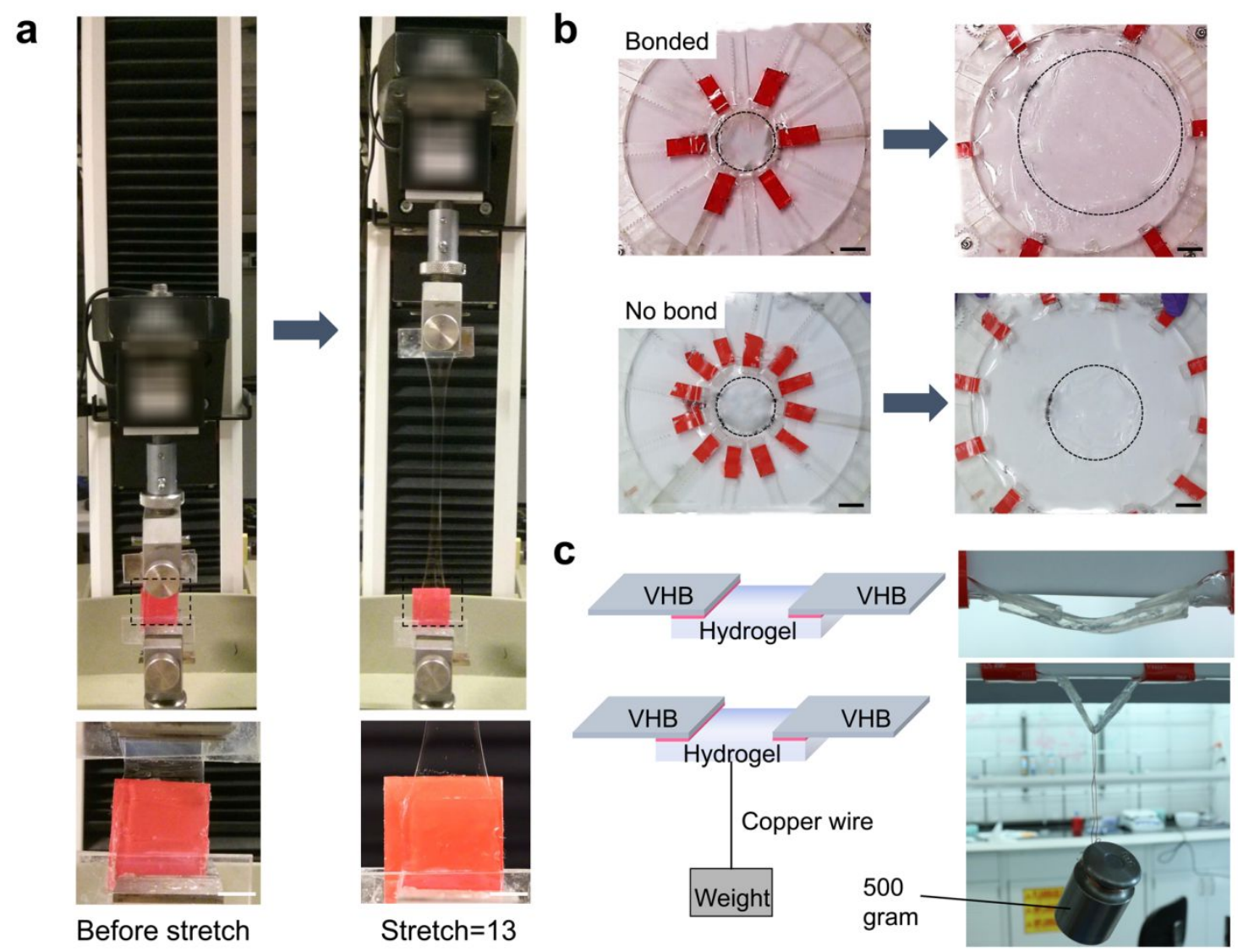

Figure S5. Mechanical robustness of chitosan-bonded PAAM hydrogel and VHB elastomer. (a) Uniaxial stretch of a PAAM hydrogel bonded on a VHB elastomer. The hydrogel is stretched as large as 13 times its initial length without debonding. The scale bar is $1 \mathrm{~cm}$. (b) Top: When a PAAM hydrogel is bonded on a VHB elastomer, the PAAM hydrogel remains strong bonded when the VHB elastomer is equi-biaxially stretched with area change as large as 16 times. Bottom: if no bonding is created between the PAAM hydrogel and the VHB elastomer, the PAAM hydrogel readily detaches from the VHB elastomer at small equi-biaxial stretch of the VHB elastomer. The black dash circle delineates the boundary of the hydrogel. The scale bar is $2 \mathrm{~cm}$. (c) A hybrid of alg-PAAM hydrogel and VHB elastomer can at least sustain a weight of $500 \mathrm{~g}$. 
a

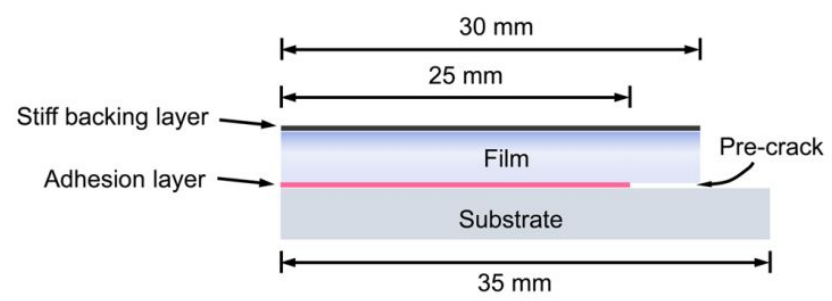

b

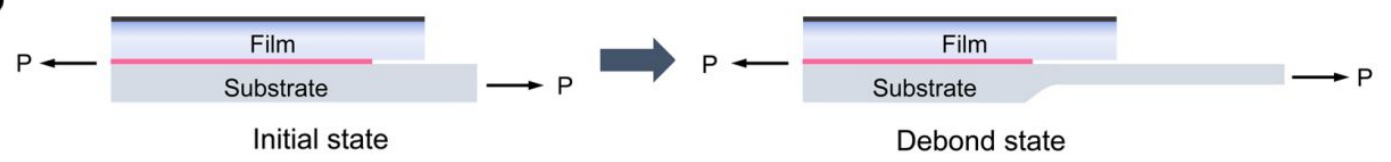

C

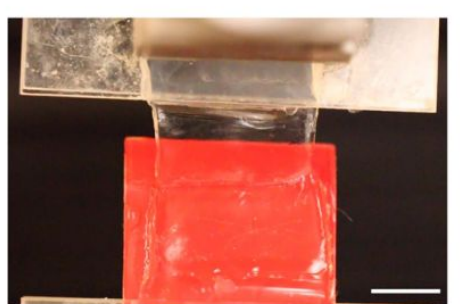

Initial state

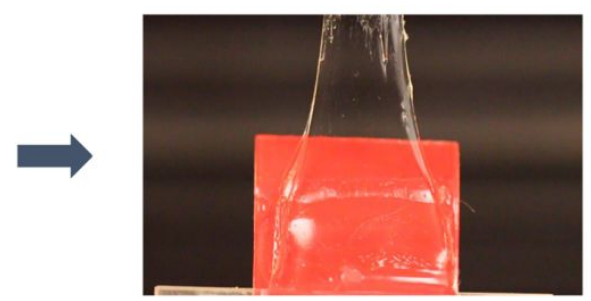

Debond state

d

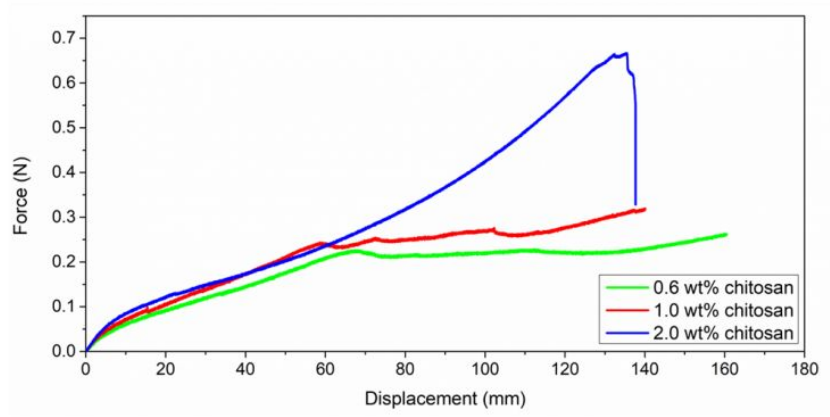

Figure S6. The bilayer adhesion test. (a) Dimensions of a hydrogel-adherend bilayer. (b) Schematics of the bilayer adhesion test. (c) Photos of the bilayer adhesion test. The scale bar is 1 $\mathrm{cm}$. (d) Representative force-displacement curves of the bilayer adhesion test. 


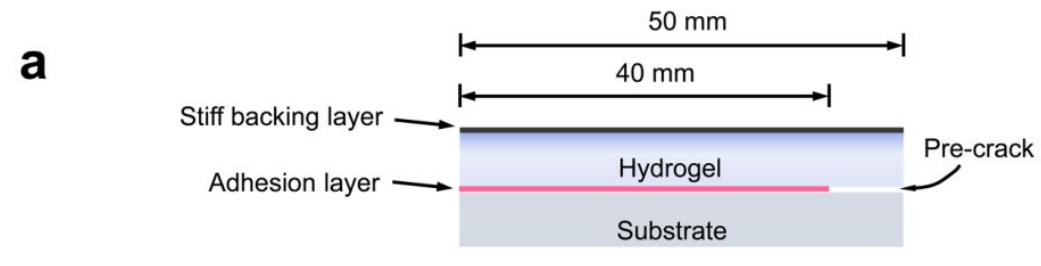

b

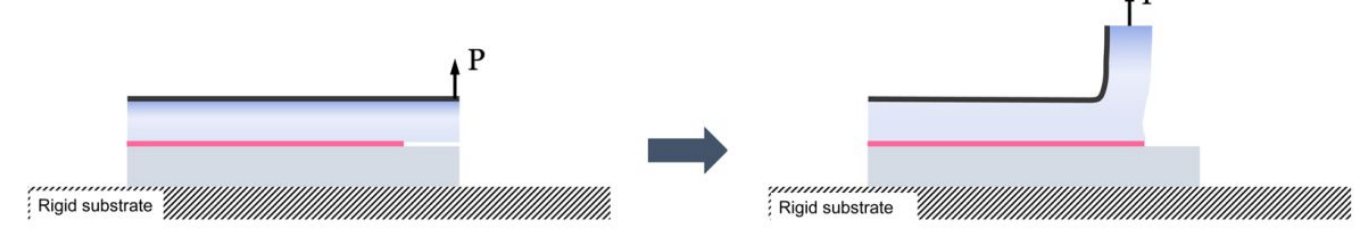

C

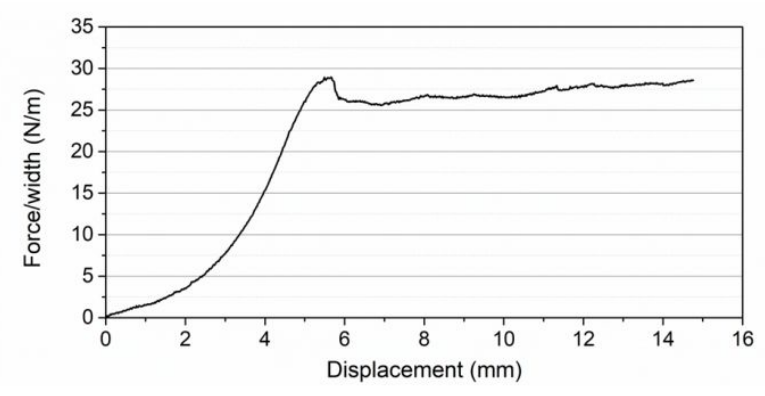

Figure S7. The 90-degree peeling test. (a) Dimensions of a hydrogel-adherend bilayer. (b) Schematics of the 90-degree peeling test. (c) A representative force-displacement curve of the 90degree peeling test. The adhesion energy is calculated as the average peeling force at plateau divided by the width of the bilayer. 
a Formation of bonds

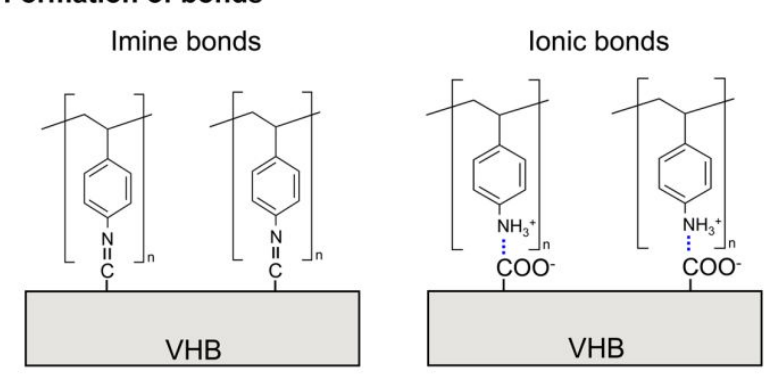

b) Formation of stitching network

Solution $(\mathrm{pH}<4.6)$

Network $(\mathrm{pH}>4.6)$
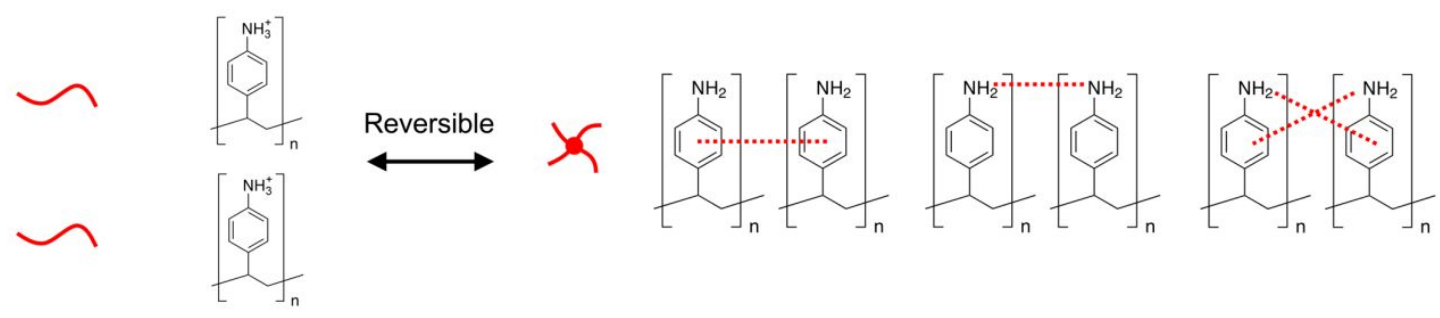

Figure S8. Chemistry of bonds and stitches with poly(4-aminostyrene). (a) Poly(4-aminostyrene) chains form imine bonds and ionic bonds on the VHB elastomer. (b) Poly(4-aminostyrene) chains dissolve in water when $\mathrm{pH}<4.6$, and crosslink into a network through $\pi-\pi$ stacking and hydrogen bonds when $\mathrm{pH}>4.6$. 


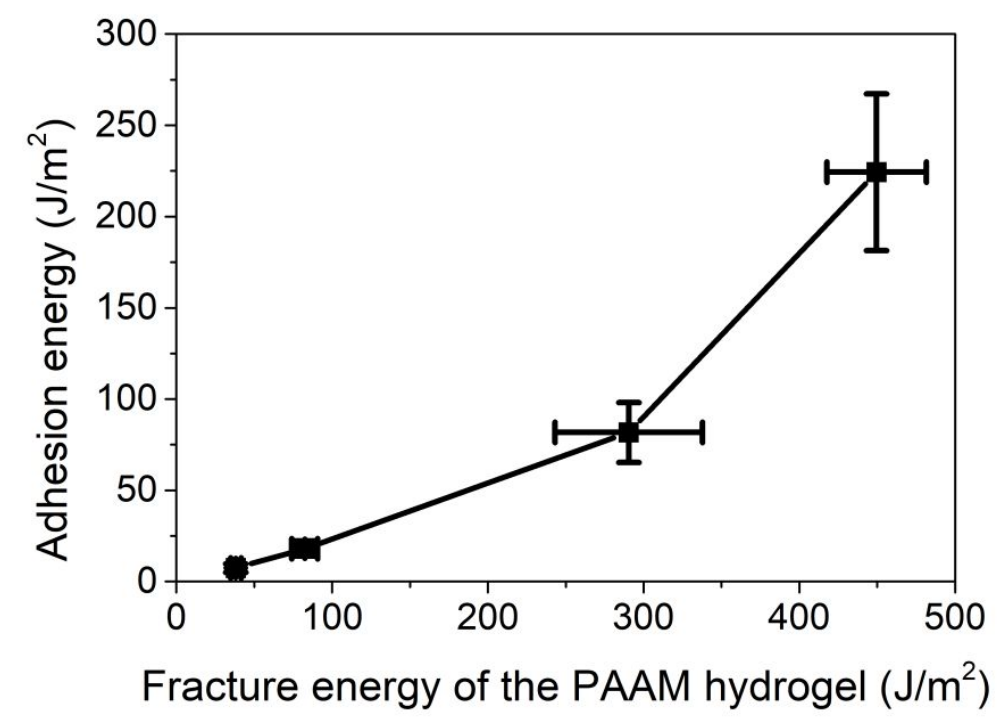

Figure S9. Adhesion energy increases with the fracture energy of the PAAM hydrogel. The facture energy of the hydrogel is varied by tuning the crosslink density of the PAAM hydrogel. The fracture energies of $450 \mathrm{~J} / \mathrm{m}^{2}, 290 \mathrm{~J} / \mathrm{m}^{2}, 82.5 \mathrm{~J} / \mathrm{m}^{2}$ and $38.2 \mathrm{~J} / \mathrm{m}^{2}$ are measured using PAAM hydrogel with MBAA to acrylamide weight ratio of 0.0006:1, 0.0012:1, 0.0016:1 and 0.002:1, respectively. The data represent the mean and standard deviation of 3-5 experimental results. 

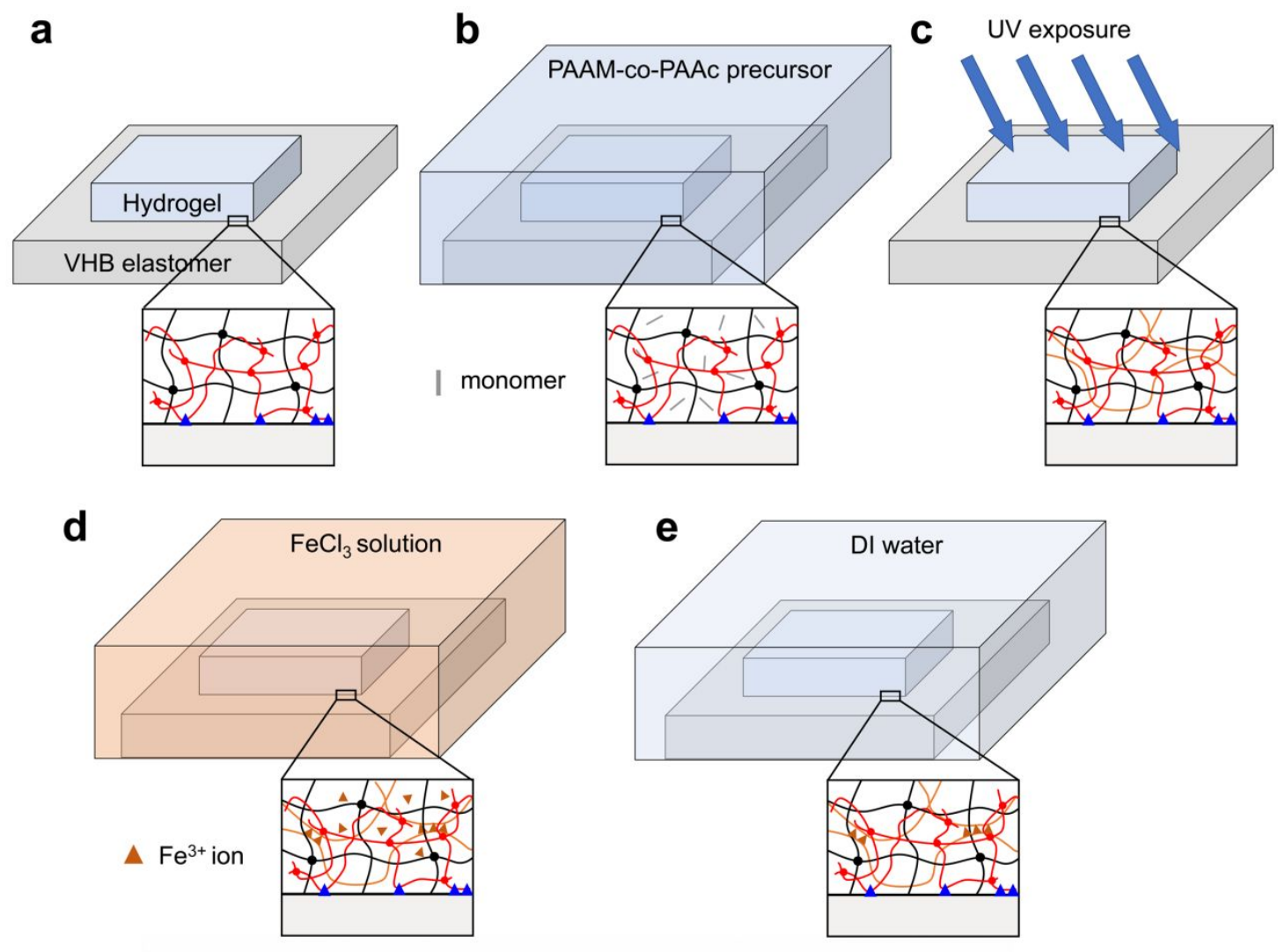

f

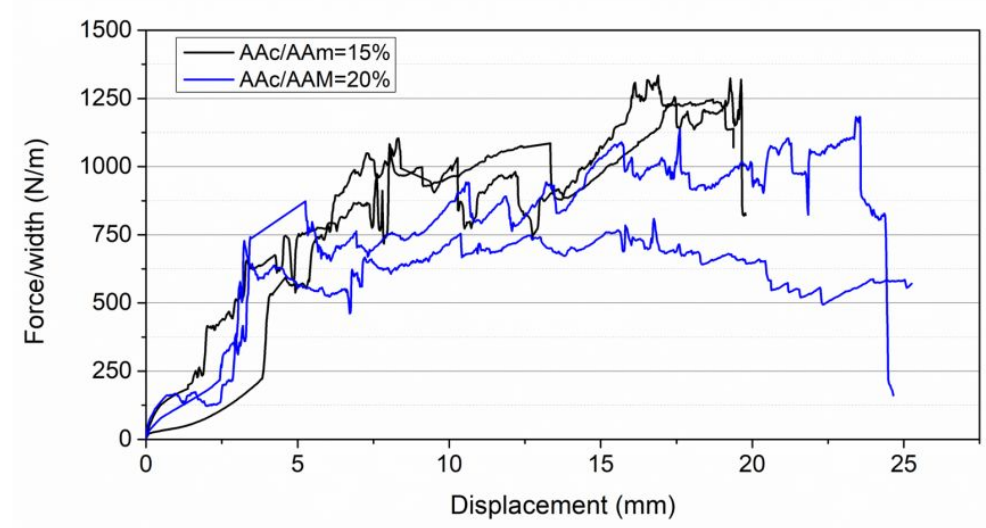

Figure S10. Amplification of adhesion energy using an iron-polyacrylate-PAAM hydrogel. (a) A PAAM hydrogel is bonded on a VHB elastomer with chitosan chains. (b) The bilayer is immersed in a PAAM-co-PAAc precursor for one day. (c) The precursor polymerizes under UV irradiation, and forms PAAM-co-PAAc copolymers that interpenetrate with the PAAM network. (d) The sample is immersed in $\mathrm{FeCl}_{3}$ solution for one day. The $\mathrm{Fe}^{3+}$ ions form coordination complex with the carboxylic acid groups, and crosslinks PAAM-co-PAAc copolymers into a PAAM-co-PAAc network. The hydrogel turns brown after the crosslinking. (e) The sample is then immersed in DI water for three days to remove the excess $\mathrm{Fe}^{3+}$ ions. (f) Force-displacement curves of 90-degree peeling tests. The adhesion energy depends on the AAm/AAc composition, and can reach about $1,000 \mathrm{~J} / \mathrm{m}^{2}$. 


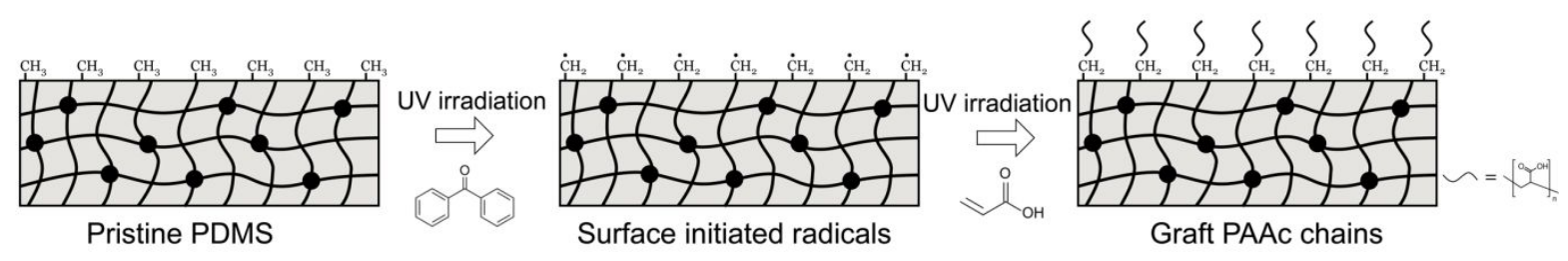

Figure S11. Surface chemical modification of silicone elastomers. A clean silicone elastomer (e.g. PDMS, Ecoflex) is first treated with benzophenone solution for $10 \mathrm{~min}$ and dried. Acrylic acid solution (2 M) is subsequently poured on the surface and exposed under UV irradiation for one hour. The acrylic acid monomers polymerize from the surface and grow into poly(acrylic acid) chains, thus modify the surface of silicone elastomer with carboxylic acid groups. 


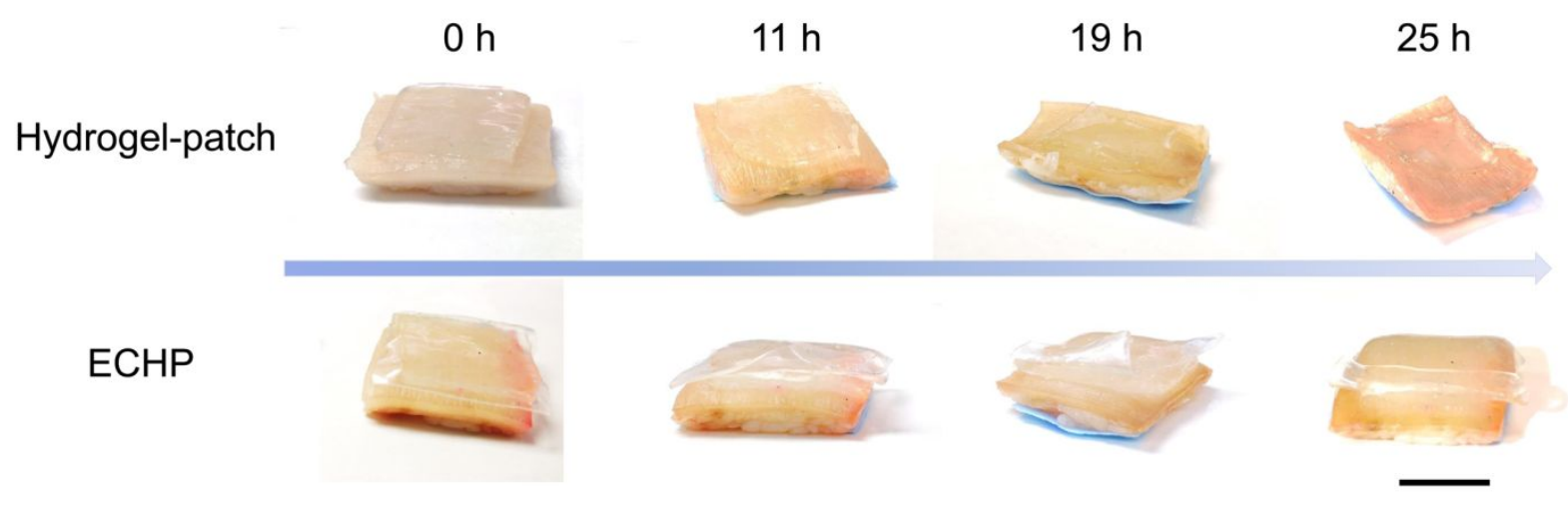

Figure S12. Dehydration of hydrogel and elastomer-coated hydrogel patch (ECHP) over time. For the hydrogel patch, dehydration occurs from both hydrogel and porcine skin. For the ECHP, dehydration is limited by top elastomer coating, and occurs from the periphery of hydrogel and porcine skin. After 25 hours, both the hydrogel patch and the porcine skin are completely dry and become hard, while the ECHP maintains relatively high water-content and is still soft. The scale bar is $1 \mathrm{~cm}$. 
Table S1. Polymer chains used in the tests

\begin{tabular}{|c|c|c|c|c|}
\hline Polymers & Molecular structure & Crosslinks of stitching network & \multicolumn{2}{|c|}{ Matching functional groups from adherend } \\
\hline Poly(4-aminestyrene) & & $\begin{array}{l}\cdot \mathrm{NH}_{2}--\mathrm{NH}_{2} \mathrm{H} \text {-bond } \\
\text { - } \mathrm{NH}_{2}--\pi \mathrm{H} \text {-bond } \\
\text { - } \pi-\pi \text { stacking }\end{array}$ & $\begin{array}{l}\text { - Carboxylic acid } \\
\text { - Hydroxyl } \\
\text { - Ketone }\end{array}$ & $\begin{array}{l}\text { - Epoxide } \\
\text { - Phenyl } \\
\text { - Negatively charged } \\
\text { surface }\end{array}$ \\
\hline Chitosan & ${ }_{\mathrm{HO}} \frac{\mathrm{NH}_{2}}{\mathrm{COH}}$ & - $\mathrm{NH}_{2}--\mathrm{OH} \mathrm{H}-$ bond & $\begin{array}{l}\text { - Carboxylic acid } \\
\text { - Hydroxyl } \\
\text { - Ketone }\end{array}$ & $\begin{array}{l}\text { - Epoxide } \\
\text { - Negatively charged } \\
\text { surface }\end{array}$ \\
\hline Polyallylamine & & NA & $\begin{array}{l}\text { - Carboxylic acid } \\
\text { - Hydroxyl } \\
\text { - Ketone }\end{array}$ & $\begin{array}{l}\text { - Epoxide } \\
\text { - Negatively charged } \\
\text { surface }\end{array}$ \\
\hline Polyethylenimine & & NA & $\begin{array}{l}\text { - Carboxylic acid } \\
\text { - Hydroxyl } \\
\text { - Ketone }\end{array}$ & $\begin{array}{l}\text { - Epoxide } \\
\text { - Negatively charged } \\
\text { surface }\end{array}$ \\
\hline Alginate & 等 & $\begin{array}{l}\cdot \mathrm{COOH}-\mathrm{-OH} \text {-bond } \\
\cdot \mathrm{COOH}-\mathrm{COOH} \mathrm{H}-\text { bond }\end{array}$ & & NA \\
\hline Polyacrylamide & & NA & & NA \\
\hline
\end{tabular}


Table S2. Hydrogels used in the tests

\begin{tabular}{|c|c|c|c|}
\hline Polymer chain of hydrogel & Molecular structure & Charges on polymer chains & Interaction with chitosan \\
\hline $\begin{array}{c}\text { Poly(hydroxyethylmethacrylate) } \\
\text { (PHEMA) }\end{array}$ & & Neutral & Weak hydrogen bond \\
\hline Poly(acrylamide) (PAAM) & & Neutral & Weak hydrogen bond \\
\hline $\begin{array}{l}\text { Poly(dimethylacrylamide) } \\
\text { (PDMA) }\end{array}$ & & Neutral & Weak hydrogen bond \\
\hline $\begin{array}{c}\text { Poly(N-isopropylacrylamide) } \\
\text { (PNIPAM) }\end{array}$ & & Neutral & Weak hydrogen bond \\
\hline Sodium polyacrylate (NaPAA) & & Negatively charged & $\begin{array}{l}\text { Weak hydrogen bond and } \\
\text { ionic bond }\end{array}$ \\
\hline $\begin{array}{l}\text { [2-(Acryloyloxy)ethyl] } \\
\text { trimethylammonium chloride } \\
\text { (PDMAEA) }\end{array}$ & $\mathrm{H}_{3}$ & Positively charged & $\begin{array}{l}\text { Weak hydrogen bond and } \\
\text { positive charge repulsion }\end{array}$ \\
\hline Polyacrylamide/alginate & & Neutral/Negatively charged & $\begin{array}{l}\text { Weak hydrogen bond and } \\
\text { ionic bond }\end{array}$ \\
\hline
\end{tabular}


Table S3. Adherends used in the tests

\begin{tabular}{|c|c|c|c|}
\hline Adherends & Functional groups & Testing polymer chains & Interfacial bonding \\
\hline Glass & Hydroxyl & Chitosan & - $\mathrm{O}^{-}-\mathrm{NH}_{3}{ }^{+}$ionic bond \\
\hline $\begin{array}{l}\text { Surface treated } \\
\text { Ecoflex }\end{array}$ & \multirow{2}{*}{ Carboxylic acid } & \multirow{2}{*}{ Chitosan } & \multirow{2}{*}{ - $\mathrm{COO}^{-}-\mathrm{NH}_{3}{ }^{+}$ionic bond } \\
\hline $\begin{array}{l}\text { Surface treated } \\
\text { PDMS }\end{array}$ & & & \\
\hline VHB elastomer & $\begin{array}{c}\text { Ketone } \\
\text { Carboxylic acid }\end{array}$ & $\begin{array}{c}\text { Chitosan } \\
\text { Poly(4-aminostyrene) }\end{array}$ & $\begin{array}{l}\text { - } \mathrm{COO}^{-}-\mathrm{NH}_{3}{ }^{+} \text {ionic bond } \\
\text { - Imine bond }\end{array}$ \\
\hline Mica & - & Chitosan & $\begin{array}{l}\text { - lonic bond between negatively } \\
\text { charged surface and } \mathrm{NH}_{3}{ }^{+}\end{array}$ \\
\hline Epoxide-glass & Epoxide & Poly(4-aminostyrene) & $\begin{array}{l}\text { - Covalent bond }\left(\mathrm{NH}_{2} \text { - epoxide }\right. \\
\text { ring opening reaction) }\end{array}$ \\
\hline Poly(styrene) & Phenyl & Poly(4-aminostyrene) & $\begin{array}{ll}\text { - } & \pi-\pi \text { stacking } \\
\text { - } & \mathrm{NH}_{2}-\pi \text { hydrogen bond } \\
\text { - } \mathrm{NH}_{3}{ }^{+}-\pi \text { cation- } \pi\end{array}$ \\
\hline Aluminum & Hydroxyl & Chitosan & - $\mathrm{NH}_{2}-\mathrm{OH}$ hydrogen bond \\
\hline
\end{tabular}


Movie S1. Confocal images of the chitosan distribution in the hydrogel. The PAAM hydrogel was soaked in FITC-chitosan solution for one day before taking images. The fluorescent signals were seen in the entire hydrogel, which indicated chitosan chains can diffuse into the hydrogel.

Movie S2. Confocal images of the chitosan distribution in the VHB elastomer. The VHB elastomer was soaked in FITC-chitosan solution for one day before taking images. The fluorescent signals were seen only in a thin layer, which indicates chitosan chains cannot diffuse into the VHB elastomer, but stay on its surface.

Movie S3. Elastomer-coated hydrogel patch and hydrogel patch adhered in vivo on the skin of a rat. After the adhesion procedure, both patches were transparent and bonded well on the skin despite the movements of the rat. After 12 hours, the elastomer-coated hydrogel patch remained transparent and well-bonded, but the hydrogel patch was completely dry and could be easily separated from the skin.

Movie S4. Underwater adhesion. A piece of VHB elastomer was immersed in water. A chitosan solution was directly injected on the surface of the elastomer through water. A hydrogel was immediately placed on top with gentle pressure for an hour. Afterwards, the adhesion was tested by hanging a weight. 